\title{
Comparison of Prasugrel and Clopidogrel Used as Antiplatelet Medication for Endovascular Treatment of Unruptured Intracranial Aneurysms: A Meta-Analysis
}

(D)F. Cagnazzo, (DP. Perrini, (DP.-H. Lefevre, (D) G. Gascou, (D). Dargazanli, (D) Riquelme, (DI. Derraz, (DD. di Carlo, (D)A. Bonafe, and (1) V. Costalat

\begin{abstract}
BACKGROUND: Clopidogrel is routinely used to decrease ischemic complications during neurointerventional procedures. However, the efficacy may be limited by antiplatelet resistance.

PURPOSE: Our aim was to analyze the efficacy of prasugrel compared with clopidogrel in the cerebrovascular field.

DATA SOURCES: A systematic search of 2 large databases was performed for studies published from 2000 to 2018.

STUDY SELECTION: According to the Preferred Reporting Items for Systematic Reviews and Meta-Analyses guidelines, we included studies reporting treatment-related outcomes of patients undergoing neurointerventional procedures under prasugrel, and studies comparing prasugrel and clopidogrel.
\end{abstract}

DATA ANALYSIS: Random-effects meta-analysis was used to pool the overall rate of complications, ischemic and hemorrhagic events, and influence of the dose of prasugrel.

DATA SYNTHESIS: In the 7 included studies, 682 and 672 unruptured intracranial aneurysms were treated under prasugrel (cases) and clopidogrel (controls), respectively. Low-dose $(20 \mathrm{mg} / 5 \mathrm{mg}$; loading and maintenance doses) prasugrel compared with the standard dose of clopidogrel $(300 \mathrm{mg} / 75 \mathrm{mg})$ showed a significant reduction in the complication rate $\left(\mathrm{OR}=0.36 ; 95 \% \mathrm{Cl}, 0.17-74, P=.006 ; \mathrm{I}^{2}=0 \%\right.$ ). Overall, the ischemic complication rate was significantly higher in the clopidogrel group $\left(40 / 672=6 \% ; 95 \% \mathrm{Cl}, 3 \%-13 \% ; I^{2}=83 \%\right.$ versus $\left.16 / 682=2 \% ; 95 \% \mathrm{Cl}, 1 \%-5 \% ; I^{2}=73 \% ; P=.03\right)$. Low and high loading doses of prasugrel were associated with $0.6 \%(5 / 535 ; 95 \% \mathrm{Cl}$, $\left.0.1 \%-1.6 \% ; I^{2}=0 \%\right)$ and $9.3 \%\left(13 / 147 ; 95 \% \mathrm{Cl}, 0.2 \%-18 \% ; I^{2}=60 \%\right)$ intraperiprocedural hemorrhages, respectively $(P=.001)$, whereas low and high maintenance doses of prasugrel were associated with $0 \%(0 / 433)$ and $0.9 \%\left(2 / 249 ; 95 \% \mathrm{Cl}, 0.3 \%-2 \% ; I^{2}=0 \%\right)$ delayed hemorrhagic events, respectively $(P=.001)$.

LIMITATIONS: Retrospective series and heterogeneous endovascular treatments were limitations.

CONCLUSIONS: In our study, low-dose prasugrel compared with clopidogrel premedication was associated with an effective reduction of the ischemic events with an acceptable rate of hemorrhagic complications.

ABBREVIATIONS: ASA = acetylsalicylic acid; $\mathrm{AT}=$ antiplatelet therapy; $\mathrm{CP}=$ clopidogrel; $\mathrm{PRU}=\mathrm{P} 2 \mathrm{Y} 12$ reaction unit; $\mathrm{PS}=$ prasugrel

$\mathbf{P}$ rophylactic antiplatelet therapy (AT) is widely used to prevent thromboembolic complications in patients undergoing endovascular treatment of intracranial aneurysms, especially when stent-assisted techniques are adopted. ${ }^{1}$ Clopidogrel (an inhibitor of the P2Y12 adenosine diphosphate receptors) is one of the most

Received November 14, 2018; accepted after revision January 28, 2019

From the Neuroradiology Department (F.C., P.-H.L., G.G., C.D., C.R., I.D., A.B., V.C.), University Hospital Güi de Chauliac, Centre Hospitalier Universitaire de Montpellier, Montpellier, France; and Department of Neurosurgery (P.P., D.d.C.), University of Pisa, Pisa, Italy.

Please address correspondence to Federico Cagnazzo, MD, Neuroradiology Department, CHU Güi de Chauliac, 80 Ave Augustin Fliche, 34000 Montpellier, France; e-mail: f.cagnazzo86@gmail.com common ATs adopted to minimize the risk of thromboembolic events. ${ }^{2}$ However, one of the limitations of this drug is the individual patient variability of its efficacy, with approximately $30 \%$ of patients showing clopidogrel (CP) resistance. ${ }^{3}$ Given that patients who are resistant to $\mathrm{CP}$ have a higher risk of ischemic events, different types of AT have been proposed. Prasugrel (PS) (Effient) is a new antiplatelet agent that has been used extensively among patients undergoing cardiovascular treatment. ${ }^{4}$ Like $\mathrm{CP}$, this drug works through the inhibition of the P2Y12 adenosine diphos-

Indicates article with supplemental on-line tables.

Indicates article with supplemental on-line photos.

http://dx.doi.org/10.3174/ajnr.A6004

AJNR Am J Neuroradiol 40:681-86 Apr 2019 www.ajnr.org 
phate receptors. However, different from CP, PS requires a 1-step activation, allowing more effective platelet inhibition and a lower degree of resistance. ${ }^{4}$ The experience with PS in the field of cerebrovascular diseases is still limited, and its safety and efficacy remain unclear. The aim of our meta-analysis was to investigate whether PS can be a conceivable alternative to CP during the endovascular treatment of unruptured intracranial aneurysms.

\section{MATERIALS AND METHODS Literature Search}

A comprehensive literature search of PubMed and Ovid EMBASE was conducted for studies published from January 2000 to October 2018. The Preferred Reporting Items for Systematic Reviews and Meta-Analyses ${ }^{5}$ guidelines were followed. The key words and the detailed search strategy are reported in On-line Table 1, and the studies included in our review are reported in On-line Table 2. The inclusion criteria were the following: 1) studies reporting series of patients with unruptured intracranial aneurysms endovascularly treated in whom PS was administrated as an AT; 2) studies reporting outcome comparisons between PS (cases) and CP (control) used as an AT for the endovascular treatment of unruptured intracranial aneurysms. Exclusion criteria were the following: 1) case reports, 2) review articles, 3) studies published in languages other than English, and 4) in vitro/animal studies. In cases of overlapping patient populations, only the series with the largest number of patients or the most detailed data were included. Two independent readers screened articles in their entirety to determine eligibility for inclusion. A third author solved discrepancies.

\section{Data Collection}

We extracted the following: 1) treatment-related complications, 2) type of complications, 3) clinical outcome, 4) mean P2Y12 reaction unit (PRU) value, 5) mean percentage of platelet inhibition, and 6) angiographic outcome. The reported results were compared between the PS and CP groups of patients.

Treatment-related complications were divided into the following: 1) periprocedural/early events (within 30 days) and delayed events (after 30 days); 2) transient (asymptomatic events or complete neurologic recovery) and permanent complications (symptomatic events with permanent deficits); and 3) ischemic and hemorrhagic complications. Finally, good outcome was defined as a modified Rankin Scale score of $0-2$ or a Glasgow Outcome Score of 4-5, or it was assumed if the study used terms such as "no morbidity," "good recovery," and "no symptoms."

\section{Outcomes}

The primary objectives of this study were to compare treatmentrelated complication rates between the PS and CP groups. The secondary objectives were to define the type of complications and the influence of the loading and maintenance doses of PS on the periprocedural and delayed hemorrhagic events, respectively.

\section{Quality Scoring}

The Newcastle-Ottawa Scale ${ }^{6}$ was used for the quality assessment of the included studies (details in On-line Tables 3 and 4). The quality assessment was performed by 2 authors independently, and a third author solved discrepancies.

\section{Statistical Analysis}

We estimated, from each cohort, the cumulative prevalence (percentage) and 95\% confidence interval for each outcome. Heterogeneity of the data were assessed by the Higgins index $\left(\mathrm{I}^{2}\right)$, and subsequently, the DerSimonian and Laird random-effects model was applied. The graphic representation is shown by a forest plot. To evaluate the heterogeneity and bias, we analyzed the metaregression and the funnel plot that was followed by the Egger linear regression test, respectively. To verify the consistency of outcome meta-analysis results, we assessed the influence of each individual study on the summary effect estimate by the sensitivity analysis (leave-one-out approach) and the subgroups analysis. To compare the percentages of each group and to calculate the $P$ values, we used the 1-way analysis of variance and the $Z$-test when appropriate. Differences were considered significant at $P<$ .05. Meta-analysis was performed with ProMeta-2 (Internovi, Cesena, Italy) and OpenMeta[Analyst] (http://www.cebm. brown.edu/openmeta/download.html).

\section{RESULTS}

\section{Literature Review}

Studies included in our meta-analysis are summarized in On-line Table 2. The search flow diagram is shown in On-line Fig 1.

Seven studies and 1354 aneurysms/procedures (1232 patients) were included in our review. Overall, 682 unruptured aneurysms were treated endovascularly using PS (cases), whereas 672 unruptured aneurysms were treated endovascularly using CP (controls). Five studies compared treatment-related outcomes between the PS and the CP groups, ${ }^{7-10,14}$ whereas 2 studies reported series of patients exclusively treated with PS. ${ }^{12,13}$

\section{Quality of Studies}

Six studies were retrospective series, ${ }^{7,8,10,12,13}$ whereas 1 study presented a prospective design. ${ }^{9}$ Overall, 5 articles were rated as "high-quality" studies. Details of the ratings of the included studies are reported in the On-line Tables 3 and 4.

\section{Patient Population and Aneurysm Characteristics}

Detailed characteristics of the patient population are reported in On-line Table 5. The mean age of patients was comparable between the 2 groups. The proportion of male patients was higher among the PS group (56\%; 95\% CI, 51\%-59\% versus $45.6 \%$; $95 \%$ CI, $41 \%-49 \% ; P=.001$ ), as well as the proportion of aneurysms in the anterior circulation $(87 \%$; $95 \%$ CI, $84 \%-89 \%$ versus $82 \%$; 95\% CI, 78\%-85\%) $(P=.01)$. Posterior circulation aneurysms were more common among the CP group (18\%; 95\% CI, $14 \%-$ $21 \%$ versus $13 \%$; 95\% CI, $10 \%-15 \%)(P=.01)$. Mean aneurysm size was comparable between the 2 groups. The proportion of aneurysms treated with stent-assisted coiling or flow diversion was higher among the PS group (63.6\%; 95\% CI, 58\%-67\% versus $54.7 \%$; 95\% CI, 50\%-58\%) $(P=.001)$.

In 4 studies, ${ }^{8,13,14}$ the loading dose of PS was $20 \mathrm{mg} 1$ day before treatment; in one study ${ }^{9}$ it was $30 \mathrm{mg} 1$ day before treatment; in 2 studies, ${ }^{10,12}$ the loading dose was between 40 and $60 \mathrm{mg}$ 
1 day before treatment; and in 1 study, ${ }^{7} 60 \mathrm{mg}$ of PS was associated with $325 \mathrm{mg}$ of acetylsalicylic acid (ASA). In 3 studies, CP, $75 \mathrm{mg}$, was combined with ASA, $100 \mathrm{mg}^{7,9}$ or ASA, $325 \mathrm{mg}^{10}, 5$ days before treatment, whereas CP, $300 \mathrm{mg}$, was used alone in 2 studies $^{8,14} 5$ days before the procedure. The maintenance dose of PS was $5 \mathrm{mg} /$ day in 3 studies, ${ }^{8,13,14} 5-10 \mathrm{mg} /$ day in 2 studies, ${ }^{9,12}$ and $10 \mathrm{mg} /$ day in 2 studies. $^{7,10}$ The maintenance dose of AT in the $\mathrm{CP}$ group was $\mathrm{CP}, 75 \mathrm{mg} / \mathrm{day},+\mathrm{ASA}, 75-100 \mathrm{mg} / \mathrm{day}$, in 4

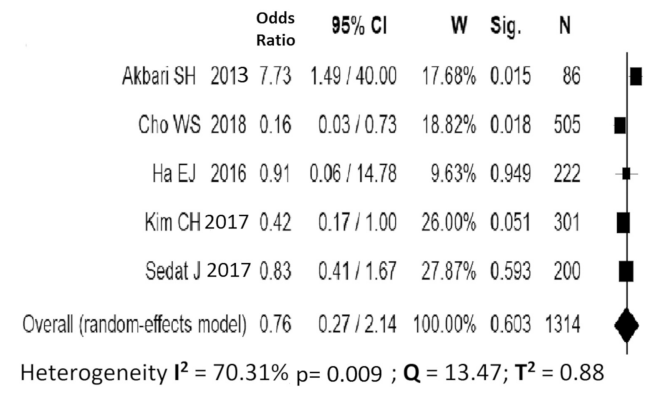

FIG 1. Forest plot with the random-effects model demonstrating the overall effect (odds ratio) of prasugrel versus clopidogrel on the treatment-related complication rate.

\section{Sensitivity Analysis (Random-effect model)}

\begin{tabular}{|c|c|c|c|c|c|c|}
\hline & $\begin{array}{l}\text { Odds } \\
\text { Ratio }\end{array}$ & $95 \% \mathrm{Cl}$ & Sig. & $\mathrm{N}$ & N1 & N2 \\
\hline Akbari SH 2013 & 0.51 & $0.26 / 0.99$ & 0.047 & 1240 & 613 & 627 \\
\hline Cho WS 2018 & 1.07 & $0.36 / 3.17$ & 0.897 & 809 & 365 & 444 \\
\hline Ha EJ 2016 & 0.76 & $0.24 / 2.38$ & 0.633 & 1104 & 528 & 576 \\
\hline Kim CH 2017 & 0.96 & $0.23 / 4.10$ & 0.958 & 1025 & 526 & 499 \\
\hline Sedat J 2017 & 0.78 & $0.16 / 3.89$ & 0.764 & 1126 & 544 & 582 \\
\hline
\end{tabular}

studies, ${ }^{8-10,14}$ whereas in 1 study CP, $75 \mathrm{mg} /$ day, was associated with ASA, $325 \mathrm{mg} /$ day. $^{7}$

The VerifyNow P2Y12 assay (Accumetrics, San Diego, California) was used to test the platelet activity in all the reported studies (in 1 series, there were no data about the platelet function testing ${ }^{10}$ ).

The mean radiologic follow-up was 14 months (range, 12-24 months; median, 12 months; interquartile range $=12-24$ months) and 13 months (range, 12-22 months; median, 12 months; interquartile range $=12-22$ months) among the PS and CP groups, respectively. The mean clinical follow-up was 15 months for both groups.

\section{Treatment-Related Outcomes among PS and CP Groups}

Treatment-related complications were analyzed with random-effect meta-analysis because this model incorporates heterogeneity among studies. When we included all series comparing PS and CP (5 studies ${ }^{7-10,14}$ ), AT with PS was not significantly associated with a reduction of the overall rate of treatment-related complications $\left(\mathrm{OR}=0.76 ; 95 \% \mathrm{CI}, 0.27-2.14 ; P=.603 ; \mathrm{I}^{2}=70.31 \%\right)($ Fig 1$)$. The funnel plot followed by the Egger linear regression test excluded publication bias $(P=.798)$. Meta-regression showed a significant variation of the effect size $(P=.001)$ during the investigated period (from 2013 to 2018) (Online Fig 2). The sensitivity analysis (Fig 2 and On-line Fig 3), removing 1 study at a time, showed that the removal of the study of Akbari et al, ${ }^{7}$ was associated with a significant reduction of the overall complication rates with the use of PS $(\mathrm{OR}=0.51 ; 95 \% \mathrm{CI}, 0.26-0.99 ; P=$ $\left..047 ; \mathrm{I}^{2}=32.5 \%\right)$. This study reported the highest dose of AT: loading-dose of $60 \mathrm{mg}$ of PS + $325 \mathrm{mg}$ of ASA and maintenance dose of $10 \mathrm{mg}$ of PS $+325 \mathrm{mg}$ of ASA.

The aneurysm occlusion rate was comparable between the 2 groups $(\mathrm{OR}=$ $1.21 ; 95 \%$ CI, $0.43-3.39 ; P=.723 ; \mathrm{I}^{2}=$ $60.2 \%$ ) (Table).

FIG 2. Sensitivity analysis (leave-one-out meta-analysis) with the random-effects model showing a significant reduction (odds ratio) of the treatment-related complications with the use of PS compared with CP after the removal of the study of Akbari et al. ${ }^{7}$

\begin{tabular}{|c|c|c|c|c|c|}
\hline Type of Complications ${ }^{a}$ & PS Group (95\% Cl) & $\begin{array}{l}\text { No. of } \\
\text { Articles }\end{array}$ & CP Group (95\% CI) & $\begin{array}{c}\text { No. of } \\
\text { Articles }\end{array}$ & $\begin{array}{c}P \\
\text { Value }\end{array}$ \\
\hline Permanent complications & $6 / 651=1 \%(1-4)\left(1^{2}=19 \%\right)$ & 6 & $11 / 617=2 \%(1-4)\left(1^{2}=81 \%\right)$ & 12 & .6 \\
\hline Ischemic/thromboembolic & $16 / 682=2 \%(1-5)\left(1^{2}=73 \%\right)$ & 7 & $40 / 672=6 \%(3-13)\left(1^{2}=83 \%\right)$ & 5 & $.003^{b}$ \\
\hline Hemorrhagic & $17 / 682=3 \%(1-9)\left(1^{2}=73 \%\right)$ & 7 & $16 / 672=3 \%(1-5)\left(1^{2}=19 \%\right)$ & 5 & .7 \\
\hline Periprocedural complications & $23 / 682=4 \%(1-11)\left(I^{2}=80 \%\right)$ & 7 & $35 / 672=5 \%(2-11)\left(1^{2}=82 \%\right)$ & 5 & .7 \\
\hline Delayed complications & $12 / 682=3 \%(1-6)\left(1^{2}=41 \%\right)$ & 7 & $23 / 672=3 \%(1-8)\left(1^{2}=71 \%\right)$ & 5 & .8 \\
\hline Treatment-related mortality & $0 / 682$ & 7 & $1 / 617=0.4 \%(0.1-2)\left(1^{2}=0 \%\right)$ & 4 & .09 \\
\hline Good neurologic outcome & $631 / 635=98 \%(96-99)\left(1^{2}=5 \%\right)$ & 6 & $606 / 617=97 \%(97-99)\left(1^{2}=20 \%\right)$ & 4 & .2 \\
\hline \multicolumn{6}{|l|}{ Platelet inhibition values ${ }^{c}$} \\
\hline Mean resistance rate & $9 / 433=1.8 \%(0.5-3)\left(1^{2}=0 \%\right)$ & 4 & $99 / 344=30 \%(23-33)\left(1^{2}=0 \%\right)$ & 2 & $.001^{b}$ \\
\hline Mean PRU & $125.2(118-132)\left(1^{2}=0 \%\right)$ & 3 & $247.8(239-256)\left(I^{2}=18 \%\right)$ & 2 & $.00^{\mathrm{b}}$ \\
\hline Aneurysm occlusion rate (PS vs CP) & \multicolumn{3}{|c|}{ Odds Ratio $=1.21\left(95 \% \mathrm{Cl}, 0.43-3.39, \mathrm{I}^{2}=60.2 \%\right)$} & 3 & .723 \\
\hline
\end{tabular}

${ }^{a}$ Complications rates were pooled using proportional meta-analysis.

b Significant.

c Platelet inhibition values were pooled using proportional meta-analysis. 


\begin{tabular}{|c|c|c|c|c|c|c|c|}
\hline & $\begin{array}{l}\text { Odds } \\
\text { Ratio }\end{array}$ & $95 \% \mathrm{Cl}$ & W & Sig. & $\mathbf{N}$ & N1 & N2 \\
\hline Cho WS 2018 & 0.16 & $0.03 / 0.73$ & $23.01 \%$ & 0.018 & 505 & 277 & 228 \\
\hline Ha EJ 2016 & 1.10 & $0.07 / 17.73$ & $6.94 \%$ & 0.949 & 222 & 106 & 116 \\
\hline Kim CH 2017 & 0.42 & $0.17 / 1.00$ & $70.05 \%$ & 0.051 & 301 & 118 & \\
\hline $\begin{array}{r}\text { PS-LD=20mg+PS-MD }=5 \mathrm{mg} \\
\text { Heterogeneity } \mathrm{I}^{2}=0\end{array}$ & $\begin{array}{c}0.36 \\
\% p=0.41\end{array}$ & $\begin{array}{c}0.17 / 0.74 \\
1 ; Q=1.83 ; T^{2}=0\end{array}$ & $100.00 \%$ & 0.006 & 1028 & 501 & \\
\hline Akbari SH & 7.73 & $1.49 / 40.00$ & $44.25 \%$ & 0.015 & 86 & 31 & \\
\hline Sedat J 2017 & 0.83 & $0.41 / 1.67$ & $55.75 \%$ & 0.593 & 200 & 100 & \\
\hline $\begin{array}{r}\text { PS-LD }=60 \mathrm{mg}+\mathrm{PS}-\mathrm{MD}=10 \mathrm{mg} \\
\text { Heterogeneity } \mathrm{I}^{2}=83 .\end{array}$ & $\begin{array}{l}\text { g } 2.22 \\
3.38 p=0 .\end{array}$ & $\begin{array}{c}0.25 / 19.59 \\
014 ; Q=6.02 ; T^{2}=\end{array}$ & $\begin{array}{l}100.00 \% \\
2.09\end{array}$ & 0.472 & 286 & 131 & \\
\hline
\end{tabular}

FIG 3. Subgroup analysis of the low and high doses of PS versus a standard dose of CP. Low-dose PS was associated with a significant reduction (odds ratio) of the treatment-related complication rate compared with $\mathrm{CP}$.

\section{Subgroup Analysis: Relationship between the Dose of PS and Treatment-Related Complications}

Studies comparing PS and CP were dichotomized into 2 groups (low-dose versus high-dose) based on the PS loading (20 versus 60 $\mathrm{mg}$ ) and maintenance doses (5 versus $10 \mathrm{mg}$ ) (Fig 3). Subgroup analysis of studies reporting a low dose $\left(20 \mathrm{mg} / 5 \mathrm{mg}\right.$ ) of $\mathrm{PS}^{8,9,14}$ (the series of Kim et $\mathrm{al}^{9}$ was the only study reporting $30 \mathrm{mg}$ of PS as loading dose) showed a significant reduction in the complication rate $\left(\mathrm{OR}=0.36 ; 95 \% \mathrm{CI}, 0.17-74 ; \mathrm{P}=.006 ; \mathrm{I}^{2}=0 \%\right)$. On the contrary, meta-analysis of studies reporting a high dose $(60 \mathrm{mg} / 10 \mathrm{mg})$ of $\mathrm{PS}^{7,10}$ showed higher odds of complications among the PS group, though this result was not statistically significant $(\mathrm{OR}=2.22 ; 95 \%$ CI, $0.25-19.59 ; P=.472 ; \mathrm{I}^{2}=83.38 \%$ ).

Low and high loading doses of PS were associated with $0.6 \%$ (5/535; 95\% CI, 0.1\%-1.6\%; $\left.\mathrm{I}^{2}=0 \%\right)$ and $9.3 \%(13 / 147 ; 95 \% \mathrm{CI}$, $0.2 \%-18 \% ; \mathrm{I}^{2}=60 \%$ ) intraprocedural/very early (within 24 hours) hemorrhagic events, respectively $(P=.001)$. Low and high maintenance doses of PS were associated with $0 \%(0 / 433)$ and $0.9 \%\left(2 / 249 ; 95 \%\right.$ CI, 0.3\%-2\%; $\left.\mathrm{I}^{2}=0 \%\right)$ hemorrhagic events during follow-up, respectively $(P=.001)$ (On-line Table 6).

\section{Subgroups of Treatment-Related Complications}

When we investigating data about the type of complications retrieved from all the included series ( 7 studies), the rates of periprocedural complications, delayed complications, hemorrhagic events, treatment-related morbidity/mortality, and good neurologic outcome were comparable between the 2 groups $(P>.05)$ (Table). On the contrary, the ischemic complication rate was significantly higher among the $\mathrm{CP}$ group $\left(40 / 672=6 \%\right.$; $95 \% \mathrm{CI}, 3 \%-13 \% ; \mathrm{I}^{2}=83 \%$ versus $\left.16 / 682=2 \% ; 95 \% \mathrm{CI}, 1 \%-5 \% ; \mathrm{I}^{2}=73 \% ; P=.003\right)$. When we compared the PS and CP groups, the PRU values were 125.2 (95\% CI, $\left.118-132 ; \mathrm{I}^{2}=0 \%\right)$ and $247.8\left(95 \% \mathrm{CI}, 239-256 ; \mathrm{I}^{2}=18 \% ; P=\right.$ $.001)$ and the mean platelet resistance rates were $1.8 \%(9 / 433 ; 95 \%$ CI, $\left.0.5 \%-3 \% ; \mathrm{I}^{2}=0 \%\right)$ and 30\% (99/344; 95\% CI, 23\%-33\%; $\mathrm{I}^{2}=$ $0 \%)(P=.001)$, respectively. Meta-regression (On-line Fig 4$)$ showed a trend toward a significant association between the ischemic complication rate and the PRU value $(P=.06)$.

In both the prasugrel and clopidogrel groups, treatment-related complications were higher among patients treated with flow diverters or stent-assisted coiling, compared with those treated with coiling or balloon-assisted coiling. Among the prasugrel group, the overall complication rates were $7 \%(22 / 254 ; 95 \%$ CI, $\left.2 \%-13 \% ; \mathrm{I}^{2}=70 \%\right)$ and $1.1 \%(3 / 281$; 95\% CI, 0.5\%-13\%; $\mathrm{I}^{2}=0 \%$ ) after treatment with stents/flow diverters and coiling, respectively. Among the clopidogrel group, the overall complication rates were $10 \%\left(28 / 265 ; 95 \%\right.$ CI, 3\%-20\%; $\mathrm{I}^{2}=$ $90 \%)$ and $2 \%(5 / 247 ; 95 \%$ CI, $0.1 \%-4 \%$; $\left.\mathrm{I}^{2}=0 \%\right)$ after treatment with stents/flow diverters and coiling, respectively (On-line Table 7).

\section{Study Heterogeneity}

Substantial heterogeneity $(>50 \%)$ was noted for the overall effect size of treatment-related complications (Fig 1) and the complication rate among the subgroup of high-dose PS (Fig 3). Among the subtypes of complications, substantial heterogeneity was reported for ischemic and periprocedural complications, permanent and delayed complications (CP group), and hemorrhagic complications (PS group) (Table). Heterogeneity was also reported for the analysis of the aneurysm occlusion rate.

\section{DISCUSSION}

Our meta-analysis of 1354 unruptured intracranial aneurysms highlighted several important findings comparing PS with CP used as an AT for endovascular treatment. Both sensitivity and subgroup analysis demonstrated that low-dose PS (loading and maintenance doses with 20 and $5 \mathrm{mg}$, respectively) was associated with a reduction of the overall rate of treatment-related complications. In addition, intra-, periprocedural, and delayed hemorrhagic events were significantly lower when the low-dose PS was used instead of the high-dose. Overall, the ischemic complication rate was significantly lower among the PS group (2\% versus $6 \%$, $P=.003$ ), and it is likely related to the lower PRU value after treatment with PS. Because clinical data of PS are limited in the field of cerebrovascular pathology, these findings are important, suggesting that low-dose PS can be safe and effective compared with $\mathrm{CP}$ premedication in patients undergoing endovascular treatment of intracranial aneurysms.

Previous series have demonstrated that premedication with CP (irreversible P2Y12 inhibitor) was associated with a reduction of the treatment-related ischemic events during cerebrovascular intervention. ${ }^{2}$ While approximately $85 \%$ of CP is hydrolyzed to an inactive metabolite, about $15 \%$ of the drug is converted in the liver into the active form through the activity of the cytochrome P450 enzymes. ${ }^{3}$ One of the main shortcomings of this drug is the variable responsiveness of individuals, related to a genetic polymorphism of cytochrome P450 2C19, one of the hepatic cytochrome $\mathrm{P} 450$ enzymes. ${ }^{15}$ Accordingly, almost $30 \%$ of patients are biochemically CP-resistant, partially due to enzyme or P2Y12 receptor polymorphisms. ${ }^{3}$ Higher PRU values have been associated with increased thromboembolic complications both after percutaneous coronary intervention ${ }^{16}$ and in the neurointerventional field. ${ }^{17}$

PS is a third-generation thienopyridine (P2Y12 receptor an- 
tagonist) largely used for coronary heart disease because it is associated with high efficacy and a notable decrease of ischemic events. ${ }^{4}$ Indeed, PS is rapidly converted into the active metabolite in 1 step, without dead-end inactive pathways, with a faster onset of action and less variability in response. ${ }^{4}$ However, data about the use of PS for the treatment of cerebrovascular disease are scanty and heterogeneous. One of the first series was described in 2013 by Akbari et al. ${ }^{7}$ The author reported 22\% and 4\% of treatment-related complications in the PS and CP groups, respectively. Most complications (85\%) in the PS group were hemorrhagic events. In this study, PS, $60 \mathrm{mg}$, + ASA, $325 \mathrm{mg}$, were used 1 day before the treatment, whereas PS, $20 \mathrm{mg}$, was used as a maintenance dose. However, more recent series reporting lower doses of PS showed different results. Comparing low-dose PS and a standard dose of CP in a large series of 277 (PS group) and 228 (CP group) intracranial aneurysms treated endovascularly, Cho et $\mathrm{al}^{8}$ reported approximately $1 \%$ and $4 \%$ treatment-related complications, respectively. Similar results were achieved by other authors reporting low-dose PS with 20 and $5 \mathrm{mg}$ used as loading and maintenance doses, respectively. . $^{9}, 13,14$

To our knowledge, our meta-analysis is the largest study comparing the outcomes of low-dose and high-dose PS versus standard-dose CP. First, the leave-one-out sensitivity metaanalysis (it was performed by iteratively removing 1 study at a time) showed that the exclusion of the series of Akbari et $\mathrm{al}^{7}$ resulted in a significant reduction in the overall complication rate with the use of $\mathrm{PS}(\mathrm{OR}=0.51 ; 95 \% \mathrm{CI}, 0.26-0.99 ; P=$ $.047)$ with low heterogeneity among studies $\left(\mathrm{I}^{2}=32.5 \%\right)$. As described above, this study on the series of Akbari et $\mathrm{al}^{7}$ reported the highest dose of AT with a not negligible rate of hemorrhagic events. These findings are in accordance with the concern that larger doses of PS can be associated with higher cerebrovascular hemorrhagic risk. Accordingly, because this was one of the main concerns with the use of PS in the cerebrovascular field, we performed a subgroups analysis investigating the influence of the drug doses on the hemorrhagic intra-, periprocedural, and delayed events, based on the loading and maintenance doses of PS, respectively. Most interesting, we found that $20 \mathrm{mg} / 5 \mathrm{mg}$ (low dose) of PS was associated with $<1 \%$ hemorrhagic events, compared with $40-60 \mathrm{mg} / 10$ mg (high dose), which was related to higher rates of bleeding events, especially in the perioperative period (9\%) (On-line Table 6).

In addition, the subgroup analysis confirmed a significant reduction of the overall rate of complications exclusively in the group of patients treated with low-dose PS (OR $=0.36$; 95\% CI, $\left.0.17-74 ; P=.006, \mathrm{I}^{2}=0 \%\right)($ Fig 3$)$.

Finally, in our meta-analysis, both the PRU value (125 versus 247 ) and the mean platelet resistance rates (1.8\% versus $30 \%$ ) were significantly lower in the PS group. In recent studies, lowdose PS with $20 \mathrm{mg} / 5 \mathrm{mg}$ (loading and maintenance doses) achieved stronger inhibition of platelet activity and a lower rate of resistance than the standard dose of CP $(300 \mathrm{mg} / 75 \mathrm{mg}){ }^{8,18} \mathrm{In}$ accordance with studies reporting a direct correlation between PRU values and ischemic complications, ${ }^{2,16,17}$ meta-regression of all the included studies (On-line Fig 4) found a trend toward a significant association between the ischemic complication rate and the PRU value $(P=.06)$ : The lower the PRU value, the better were outcomes in terms of ischemic complications. Accordingly, one of the main results highlighted by our meta-analysis was the effective reduction of the thromboembolic events with the use of PS: The overall rate of ischemic events was $2 \%$ and $6 \%$ in the PS and $\mathrm{CP}$ groups, respectively $(P=.003)$.

\section{Strengths and Limitations}

Our study has limitations. Most series had a retrospective design. Although the heterogeneity among studies has been, in part, explained with the sensitivity and subgroup analyses, there was heterogeneity within studies related to different endovascular techniques adopted. The influence of the intraprocedural heparin administration was not evaluated. In addition, the duration and dose of ASA in conjunction with prasugrel or clopidogrel and the length of the antiplatelet therapy were not evaluated, and they can have a significant impact on the bleeding risk. The overall effect size (reduction of the treatment-related complication rate among the prasugrel group) could be overestimated due to the search strategy and terminology. However, publication bias was reasonably excluded, and our study is the largest to date comparing PS and $\mathrm{CP}$ for the endovascular treatment of intracranial aneurysms.

\section{CONCLUSIONS}

Compared with clopidogrel premedication, low-dose prasugrel is associated with an effective reduction of ischemic events with an acceptable rate of hemorrhagic complications. Our results support prasugrel as an alternative to clopidogrel in patients undergoing endovascular treatment of unruptured intracranial aneurysms.

Disclosures: Paolo Perrini-UNRELATED: Employment: Azienda Ospedaliero Universitaria Pisana, Comments: Associate Professor of Neurosurgery, University of Pisa. Pierre-Henri Lefevre-UNRELATED: Payment for Lectures Including Service on Speakers Bureaus: Medtronic; Travel/Accommodations/Meeting Expenses Unrelated to Activities Listed: MicroVention. Vincent Costalat-UNRELATED: Consultancy: Balt, Stryker, Medtronic; Grants/Grants Pending: Medtronic, Stryker*; Payment for Development of Educational Presentations: Medtronic, Stryker, MicroVention. *Money paid to the institution.

\section{REFERENCES}

1. Yamada NK, Cross DT 3rd, Pilgram TK, et al. Effect of antiplatelet therapy on thromboembolic complications of elective coil embolization of cerebral aneurysms. AJNR Am J Neuroradiol 2007;28: 1778-82 CrossRef Medline

2. Kang HS, Han MH, Kwon BJ, et al. Is clopidogrel premedication useful to reduce thromboembolic events during coil embolization for unruptured intracranial aneurysms? Neurosurgery 2010;67: 1371-76; discussion 1376 CrossRef Medline

3. Hall R, Mazer CD. Antiplatelet drugs: a review of their pharmacology and management in the perioperative period. Anesth Analg 2011;112:292-318 CrossRef Medline

4. Wiviott SD. Intensity of antiplatelet therapy in patients with acute coronary syndromes and percutaneous coronary intervention: the promise of prasugrel? Cardiol Clin 2008;26:629-37 CrossRef Medline

5. Moher D, Liberati A, Tetzlaff J, et al; PRISMA Group. Preferred reporting items for systematic reviews and meta-analyses: the PRISMA statement. Int J Surg 2010;8:336-41 CrossRef Medline

6. Wells G, Shea B, O'Connell D. The Newcastle-Ottawa Scale (NOS) for Assessing the Quality of Nonradomized Studies in Meta-Analyses. Ottawa: Ottawa Hospital Research Institute; 2011

7. Akbari SH, Reynolds MR, Kadkhodayan Y, et al. Hemorrhagic complications after prasugrel (Effient) therapy for vascular neurointer-

AJNR Am J Neuroradiol 40:681-86 Apr 2019 www.ajnr.org

685 
ventional procedures. J Neurointerv Surg 2013;5:337-43 CrossRef Medline

8. Cho WS, Lee J, Ha EJ, et al. Low-dose prasugrel vs clopidogrel-based tailored premedication for endovascular treatment of cerebral aneurysms. Neurosurgery 2018 Aug 20. [Epub ahead of print] CrossRef Medline

9. Kim CH, Hwang G, Kwon OK, et al. P2Y12 reaction units threshold for implementing modified antiplatelet preparation in coil embolization of unruptured aneurysms: a prospective validation study. Radiology 2017;282:542-51 CrossRef Medline

10. Sedat J, Chau Y, Gaudart J, et al. Prasugrel versus clopidogrel in stent-assisted coil embolization of unruptured intracranial aneurysms. Interv Neuroradiol 2017;23:52-59 CrossRef Medline

11. Lee K, Park H, Park I, et al. Y-configuration stent-assisted coil embolization for wide-necked intracranial bifurcation aneurysms. J Cerebrovasc Endovasc Neurosurg 2016;18:355-62 CrossRef Medline

12. Stetler WR, Chaudhary N, Thompson BG, et al. Prasugrel is effective and safe for neurointerventional procedures. J Neurointerv Surg 2013;5:332-36 CrossRef Medline
13. Lee D, Song Y, Han M, et al. Low-dose prasugrel in patients with resistance to clopidogrel for the treatment of cerebral aneurysms. Neurointervention 2018;13:124-27 CrossRef Medline

14. Ha EJ, Cho WS, Kim JE, et al. Prophylactic antiplatelet medication in endovascular treatment of intracranial aneurysms: low-dose prasugrel versus clopidogrel. AJNR Am J Neuroradiol 2016;37: 2060-65 CrossRef Medline

15. Caplain H, Donat F, Gaud C, et al. Pharmacokinetics of clopidogrel. Semin Thromb Hemost 1999;25(Suppl) 2:25-28 Medline

16. Gurbel PA, Bliden KP, Samara W, et al. Clopidogrel effect on platelet reactivity in patients with stent thrombosis: results of the CREST study. J Am Coll Cardiol 2005;46:1827-32 CrossRef Medline

17. Kim B, Kim K, Jeon P, et al. Thromboembolic complications in patients with clopidogrel resistance after coil embolization for unruptured intracranial aneurysms. AJNR Am J Neuroradiol 2014;35: 1786-92 CrossRef Medline

18. Choi HH, Lee JJ, Cho YD, et al. Antiplatelet premedication for stentassisted coil embolization of intracranial aneurysms: low-dose prasugrel vs clopidogrel. Neurosurgery 2018;83:981-88 CrossRef Medline 